\title{
Molecular Characterization of Antithrombin III (ATII) Variants Using Polymerase Chain Reaction Identification of the ATIII Charleville as an Ala 384 Pro mutation
}

\author{
Pascale Molho-Sabatier, Martine Aiach, * Isabelle Gaillard, Jean-Noël Fiessinger," \\ Anne-Marie Fischer, ${ }^{5}$ Gilliane Chadeuf, ${ }^{*}$ and Eric Clauser \\ Institut National de la Santé et de la Recherche Medicale, Unit 36, 75005 Paris, ${ }^{*}$ Laboratoire d'Hémostase and ${ }^{\ddagger}$ Centre de Recherches \\ Claude Bernard sur les Maladies Vasculaires Périphériques, Hôpital Broussais, 75014 Paris; \\ and ${ }^{\S}$ Laboratoire d'Hématologie, Centre hospitalo-universitaire Necker-Enfants Malades, 75006 Paris
}

\section{Abstract}

The genes of seven structural mutants of antithrombin III (ATII), presenting either defective serine protease reactivity or abnormal heparin binding, were analyzed. The polymerase chain reaction (PCR) was used to amplify the corresponding gene exon and the mutation was identified by either dot blot analysis using a battery of allele-specific oligonucleotide probes or sequencing.

Variants Paris and Paris 2 were identified as Arg 47 Cys mutations, and Clichy, Clichy 2, and Franconville were found to be Pro 41 Leu mutations. All five are heparin binding-site variants. ATIII Avranches is an Arg 393 His mutation and ATII Charleville is an Ala 384 Pro mutation. These two mutations impair the reactive site of the molecule.

ATIII Charleville is a new mutation of the reactive center, as predicted by previous biochemical data. The position of this new mutation, together with the other previously described mutations of the reactive center, sheds light on the molecular function of this site in inhibiting thrombin.

Finally, genomic amplification by $\mathrm{PCR}$ is a powerful technique for the fast identification of antithrombin III mutations and their homozygous/heterozygous status, and should be useful for predicting thrombotic risk.

\section{Introduction}

Qualitatively deficient antithrombin III (ATIII), ${ }^{1}$ a circulating glycoprotein that plays a major role in the physiological inhibition of blood coagulation, is a classical but rare cause of thrombosis.

Identification of the mutation responsible for this deficiency is important for at least two major reasons: (a) to demonstrate a correlation between clinical events, generally recurrent thromboembolisms, and a particular molecular defect of antithrombin III; $(b)$ to provide a better understanding of the

Address reprint requests to Dr. Eric Clauser, INSERM U36, 17, rue du Fer-à-moulin, 75005 Paris, France.

Received for publication 30 March 1989 and in revised form 15 June 1989.

1. Abbreviations used in this paper: ASO, allele-specific oligonucleotide; ATIII, antithrombin III; DVT, deep venous thrombosis; WT, wild-type.

J. Clin. Invest.

(c) The American Society for Clinical Investigation, Inc.

0021-9738/89/10/1236/07 $\$ 2.00$

Volume 84, October 1989, 1236-1242 structural features responsible for the function of the protein's two functional domains: the heparin binding site located near the $\mathrm{NH}_{2}$ terminus (1), which interacts with heparin to modify the affinity of antithrombin for its protease (2), and the $\mathrm{COOH}$-terminal reactive site, which forms a covalent complex with thrombin after cleavage of the Arg 393-Ser 394 bond (3).

Identification of these mutations was, until recently, quite difficult. But the cloning and sequencing of the ATIII cDNA and gene (4-7), together with rapid improvements in the techniques of molecular biology (enzymatic amplification of genomic DNA plus dot-blot analysis with specific oligonucleotide probes) now allow direct investigation of ATIII gene abnormalities.

This report describes the diagnosis of the mutation in seven families presenting with a qualitative antithrombin deficit. Analysis of these patients provides new insights into the structure and the function of ATIII and the resulting data give a clear indication of the thrombotic risk associated with each mutation.

\section{Methods}

\section{Patients}

Five ATIII variants, referred to as heparin binding-site variants (HBS variants), were defined by their low antiprotease activity $(\leq 50 \%)$ in the presence but not the absence of heparin and normal immunoreactive ATIII. The propositi of ATIII Paris (8) and Paris 2 (9) presented with severe thrombotic complication, but all the other family members having the protein abnormality were asymptomatic. None of the three other cases had thrombosis. The Clichy abnormality was detected in a 24-yr-old woman presenting with a thoracic outlet syndrome (10). The Franconville variant was diagnosed in a 25 -yr-old woman who presented with a retroplacental hemorrhage, which led to fetal death in the 7 th mo of pregnancy. No relationship could be established between this clinical event and the defective ATIII. Her mother and two sisters had the same protein abnormality but no thrombotic history; one brother was unaffected. The Clichy 2 variant was discovered fortuitously in a 25 -yr-old woman before she started oral contraception. She had no personal or familial history of thrombosis. Three members of the ATIII Alger family (11) were also tested, and used as positive controls. One was homozygous, and the other two were heterozygous, for the Arg 47 Cys mutation. The incidence of deep venous thrombosis (DVT) in the heparin binding-site variants of our series, together with those in the literature, is shown in Table I.

Two variants, referred to as reactive-site variants, were also studied. They are defined by a low ( $\leq 50 \%)$ antiprotease activity in both the presence and absence of heparin. The clinical and biological features of these two cases have been described $(12,13)$.

\section{Materials}

Enzymes. T4 polynucleotide kinase, T4 DNA ligase, and the restriction enzyme Sma I were purchased from New England Biolabs (Bev- 
Table I. Incidence of DVT in HBS Variants

\begin{tabular}{|c|c|c|c|}
\hline Variant & Mutation & $\begin{array}{l}\text { No. of abnormal } \\
\text { subjects in the family }\end{array}$ & $\begin{array}{c}\text { No. of } \\
\text { subjects } \\
\text { with DVT }\end{array}$ \\
\hline Basel (37) & \multirow{4}{*}{ Pro 41 Leu } & \multirow{4}{*}{ Heterozygous } & 0 \\
\hline Clichy (10) & & & 0 \\
\hline Clichy $2^{*}$ & & & 0 \\
\hline Franconville* & & & 0 \\
\hline Paris (8) & \multirow{5}{*}{ Arg 47 Cys } & \multirow{3}{*}{ Heterozygous } & 1 \\
\hline Paris 2 (9) & & & 1 \\
\hline Tours $(38,39)$ & & & 0 \\
\hline \multirow[t]{2}{*}{ Toyama $(21,40)$} & & Homozygous & 1 \\
\hline & & Heterozygous & 0 \\
\hline \multirow[t]{2}{*}{ Alger (20) } & & Homozygous & 1 \\
\hline & & Heterozygous & 0 \\
\hline Rouen I (41) & Arg $47 \mathrm{His}$ & \multirow{3}{*}{ Heterozygous } & 0 \\
\hline Rouen II (25) & Arg 47 Ser & & 0 \\
\hline Rouen III (42) & Ile 7 Asn & & $1^{\ddagger}$ \\
\hline
\end{tabular}

* Unpublished.

‡ DVT occurred during an episode of heparin-induced thrombocytopenia.

Reference numbers are in parentheses.

erly, MA). Klenow fragment of $E$. coli DNA polymerase I was from Boehringer Mannheim GmBH (Mannheim, FRG). Thermus aquaticus polymerase was from Cambio (Cambridge, UK).

Deoxynucleotides. Deoxyadenosine triphosphate (dATP), deoxycytosine triphosphate (dCTP), deoxythymidine triphosphate (dTTP), and deoxyguanosine triphosphate (dGTP) were purchased from Pharmacia Fine Chemicals (Uppsala, Sweden).

\section{Experimental protocols}

Oligonucleotides were synthesized on a gene assembler (Pharmacia Fine Chemicals) using the $\beta$-cyanoethyl phosphoramidite method and purified on polyacrylamide gels. The sequences of all the oligonucleotides are summarized in Table II. The sequences of the allele-specific oligonucleotide (ASO) probes were designed according to the published mutations of different ATIII variants. When the mutation had been determined by protein sequencing, the codon presenting a single nucleotide difference from the wild type sequence was selected. These probes were $5^{\prime}$ end-labeled with $\left[{ }^{32} \mathrm{P}\right] \gamma \mathrm{ATP}$ according to Maxam and Gilbert (14) with a specific activity of $3-4 \mu \mathrm{Ci} \cdot \mathrm{pmol}^{-1}$.

Preparation of DNA samples. Peripheral blood samples from the eight patients having qualitative ATIII deficiencies and their families were collected over EDTA. The leucocytes were isolated and their DNA extracted. This DNA was purified by the method of Bell et al. (15) with minor modifications: DNA was precipitated with isopropanol, washed three times with $70 \%$ ethanol, and dried. It was dissolved over several days at $4^{\circ} \mathrm{C}$ in $1 \mathrm{mM}$ Tris $\mathrm{HCl}, 0.1 \mathrm{mM}$ EDTA and treated with RNase $(100 \mu \mathrm{g} / \mathrm{ml})$ for $3 \mathrm{~h}$, and dialyzed against the same buffer for $24 \mathrm{~h}$ at $4^{\circ} \mathrm{C}$.

Enzymatic amplification of specific genomic DNA sequences. Genomic amplification was performed essentially according to the method of Saiki et al. (16). The amplification was performed with either the Klenow fragment of Escherichia coli DNA polymerase I (first results obtained with dot-blot) or the Taq polymerase Cambio (for subcloning). Target sequences were amplified in the amplification buffer (10 mM Tris- $\mathrm{HCl}$ [pH 7.6], $10 \mathrm{mM} \mathrm{MgCl} 2,50 \mathrm{mM} \mathrm{NaCl})(100$ $\mu \mathrm{l}$ final volume) containing $1 \mu \mathrm{g}$ of genomic DNA, $1.5 \mathrm{mM}$ each of dATP, dCTP, dGTP, and dTTP, and $100 \mathrm{pmol}(1 \mu \mathrm{M})$ of each extension primer. The extension primers (Table II) were PS1B and PS2B for exon II, coding for the heparin binding site, and PS11C and PS12 for exon VI, coding for the reactive site. Samples were heated at $95^{\circ} \mathrm{C}$ for 7 min, microfuged for $10 \mathrm{~s}$, and incubated for $2 \mathrm{~min}$ at $55^{\circ} \mathrm{C}$ for Taq polymerase or $37^{\circ} \mathrm{C}$ for Klenow; $2 \mathrm{U}$ of enzyme (Klenow or Taq) were then added to each sample and the extension step was carried out at $70^{\circ} \mathrm{C}$ (Taq) or $50^{\circ} \mathrm{C}$ (Klenow) for $3 \mathrm{~min}$. A total of 25 cycles were performed, with addition of either $1 \mathrm{U}$ of Klenow at every cycle, or $2 \mathrm{U}$ of Taq polymerase at rounds 1 and 12 .

Quality control of the amplified material was performed by electrophoresis on 3\% agarose gel and Southern blot hybridization (17) with specific ASO probes (PS3 for amplified exon II and PS9 for amplified exon VI).

Dot-blot analysis. A 10- $\mu$ l aliquot of each amplified sample was denatured with $0.4 \mathrm{~N}$ sodium hydroxide and $25 \mathrm{mM}$ EDTA in a final volume of $200 \mu \mathrm{l}$, heated for $2 \mathrm{~min}$ at $95^{\circ} \mathrm{C}$, and cooled on ice. Duplicate $100-\mu$ l aliquots of each sample were placed in the wells of hybridot manifold (Bethesda Research Laboratories, Bethesda, MD) containing a nylon membrane (Biotrace RP, Gelman Sciences, Inc., Ann Arbor, MI). The samples passed through the filter under vacuum, and the filter was rinsed quickly in $2 \times \operatorname{SSPE}(1 \times \mathrm{SSPE}=0.18 \mathrm{M} \mathrm{NaCl}, 10$ $\mathrm{mM} \mathrm{NaH} \mathrm{PO}_{4}, 1 \mathrm{mM}$ EDTA, pH 7.4) and baked for $2 \mathrm{~h}$ at $+80^{\circ} \mathrm{C}$. Prehybridization $(30 \mathrm{~min})$ and hybridization with the labeled ASO probe $(1 \mathrm{~h})$ were carried out in plastic sealing bags containing $5 \times$ SSPE, $5 \times$ Denhardt's and $0.5 \%$ SDS (solution A), between 42 and $50^{\circ} \mathrm{C}$, depending on the melting temperature of the DNA duplex $\left(T_{\mathrm{m}}\right)$ of each ASO probe.

After hybridization, filters were rinsed twice with $6 \times$ SSPE, $0.1 \%$ SDS (solution 1) at room temperature, washed $10 \mathrm{~min}$ in $2 \times$ SSPE, $0.1 \%$ SDS (solution 2 ) at a temperature determined by the $T_{\mathrm{m}}$ of the probe, and then exposed to $\mathrm{x}$-ray film for $1-2 \mathrm{~h}$ at $-80^{\circ} \mathrm{C}$ with one intensifying screen (Philips Electronic Instruments, Mahwah, $\mathrm{NJ}$ ).

Subcloning and sequencing. $50 \mu \mathrm{l}$ of amplified genomic DNA was 5 ' end-phosphorylated with $1 \mu \mathrm{l} 10 \mathrm{mM}$ ATP using T4 polynucleotide kinase in $60 \mu \mathrm{l}$ (final volume) for $1 \mathrm{~h}$ at $37^{\circ} \mathrm{C}$, purified on a Nen-Sorb 20 column (New England Nuclear Research Products, DuPont Co., Wilmington, DE), lyophilized, and redissolved in $35 \mu$ l distilled water. Blunt-end ligation of $5 \mu \mathrm{l}$ of the phosphorylated samples with $50 \mathrm{ng}$ of bacteriophage M13 mp 18 digested with Sma 1 was performed for $16 \mathrm{~h}$ at $14^{\circ} \mathrm{C}$. After transformation, recombinant phages were screened with two oligonucleotide probes, which were 5 ' end-labeled with $\left[{ }^{32} \mathrm{P}\right] \mathrm{dATP}$. The probes were PS3 and PS16 for the heparin binding site, and PS9 and PS13 for the reactive site (Table II).

Prehybridization and hybridization were carried out in solution A at $42^{\circ} \mathrm{C}$ for $24 \mathrm{~h}$. The filters were then washed at $50^{\circ} \mathrm{C}$ for $30 \mathrm{~min}$ in solution 1 and $30 \mathrm{~min}$ in solution 2 . Single-stranded templates were prepared from positive recombinant bacteriophages as previously described (18).

These single-stranded templates were sequenced by the dideoxynucleotide chain termination method of Sanger (19), as modified for use with the sequenase kit (United States Biochemicals, Cleveland, $\mathrm{OH})$ and ${ }^{35} \mathrm{~S}-\mathrm{dATP}$.

\section{Results}

Exons II and VI of the ATIII genes from the seven patients and one control were amplified and resolved as single bands that hybridized with their respective specific probes (data not shown).

Identification of point mutations by dot-blot analysis. The amplified material was analyzed by dot-blot and hybridization with a series of ASO probes corresponding to either wild-type (WT) sequences (WT probes) or to mutated sequences (mutated probes). Fig. 1 shows the results for the HBS variants. All the samples, except the variant Alger a, hybridized at position 47 with the WT probe (arginine 47). Four samples (Alger a, Alger b, Paris 1, Paris 2) also hybridized with the mutated probe (cysteine 47). Thus, the variant Alger a is homozygous for the mutation (CGT) Arg 47 Cys (TGT) and Alger b is 


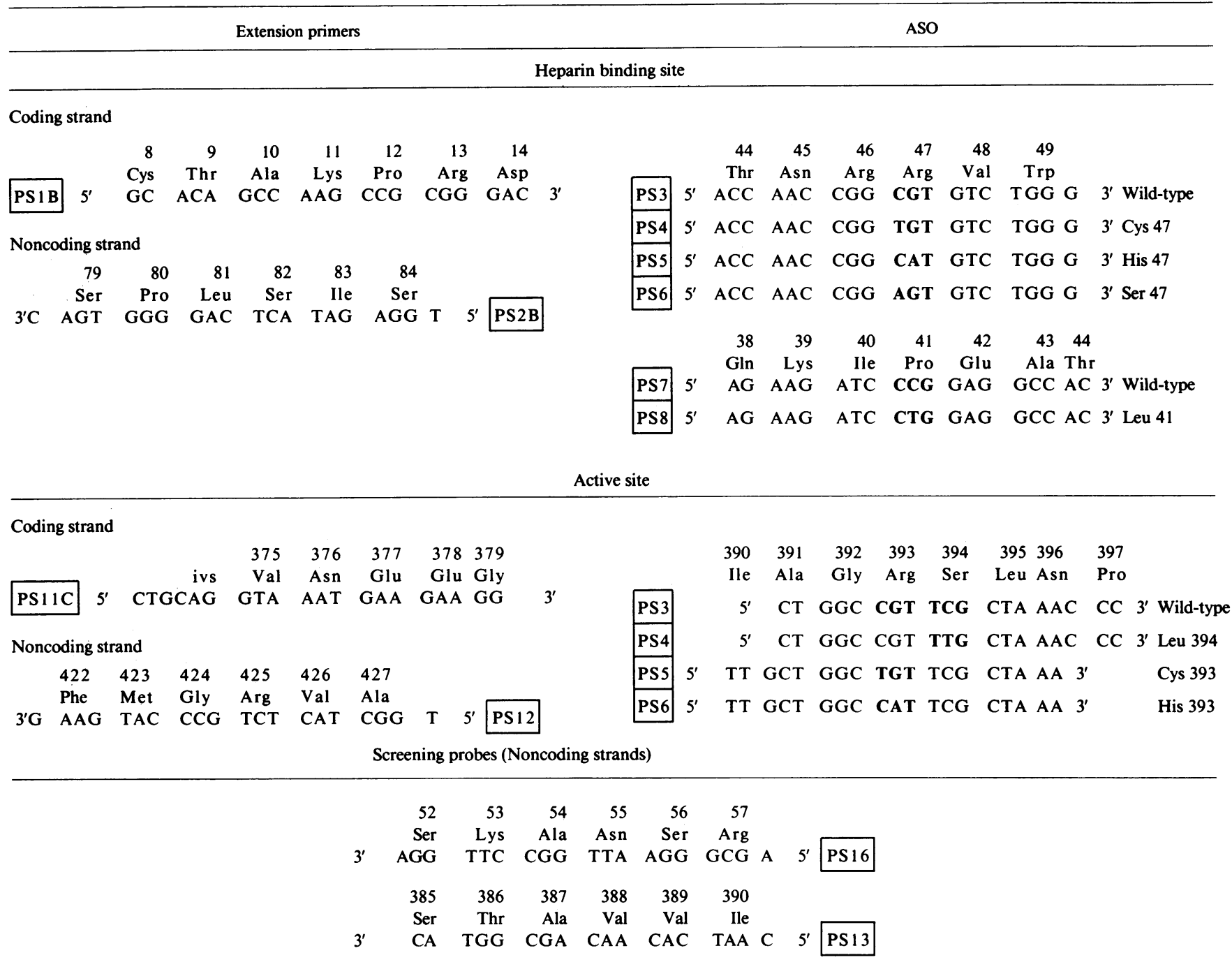

The amino acid sequence is numbered according to reference 7. Oligonucleotides in the coding strand are written from the left to the right in codons. Oligonucleotides in the noncoding strand are written from the right to the left (anticodon) intervening sequence (ivs) or intron.

heterozygous, as previously described (20). The two other variants (Paris 1 and Paris 2) are also heterozygous for the same mutation.

All the samples gave a positive signal at position 41 with the WT probe (Pro). Three variants (Clichy, Clichy 2, and Franconville) also hybridized with the mutated probe (Leu), indicating that they are heterozygous for the mutation (CCG) Pro 41 Leu (CTG).

Fig. 2 shows the dot-blot analysis of the amplified reactive site sequence. The three DNAs tested hybridized with the WT probe, but that of ATIII Avranches also hybridized with one of the mutated probes, identifying a point mutation of the cleavage site sequence, His 393-Ser 394 instead of Arg 393-Ser 394. None of the variants reacted with either the mutant leucine 394 probe or the cysteine 393 probe (data not shown).

The second active site variant (ATIII Charleville) thus was the only one for which the mutation could not be identified by dot blot using ASO to previously identified mutants.

Sequencing of amplified sequences. All the amplified DNAs were subcloned and sequenced to confirm the six mutations identified by dot-blot and to identify new mutations. The amplified region encompassing amino acids $15-78$ was sequenced for the heparin binding site and the region encompassing amino acids $380-421$ for the reactive site.

The point mutation of ATIII Avranches ([CGT] Arg 393 His [CAT]) was directly confirmed by sequencing, as were the mutation of (CCG) Pro 41 Leu (CTG) (ATIII Clichy 2 and Franconville) and the mutation (CGT) Arg 47 Cys (TGT) (ATIII Paris 1 and Paris 2). An example of sequencing of each mutation (Leu 41, Cys47 and His393) is shown in Fig. 3.

Six single-stranded templates corresponding to the amplified DNA of ATIII Charleville were also sequenced. Two of them exhibited the same point mutation in position 384 , GCA to CCA, leading to the substitution of alanine 384 for proline (Fig. $3 b$ ).

\section{Discussion}

This study was designed to identify the molecular abnormality in a series of HBS variants and in two reactive-site variants, 


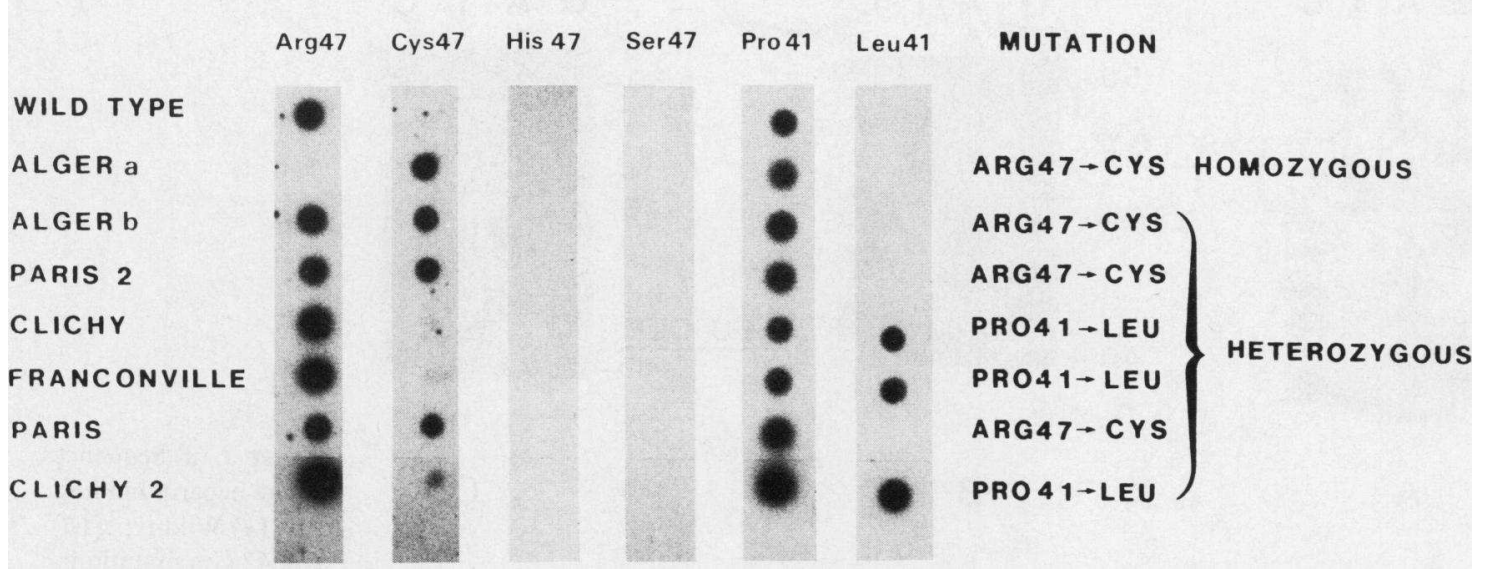

Figure 1. Analysis by dot blot of the amplified DNA from seven patients with heparin binding site abnormalities and one control DNA. (Left) Names of the different ATIII variants; (right) mutations. (Top) different ASOs are designed by the mutation that they represented. The samples were hybridized with either wild-type probes (Arg 47, Pro 41) or mutated probes (Cys 47, His 47, Ser 47, Leu 41). Heterozygous variants reacted with both the wild-type and one of the mutated probes.

and thus provide a better understanding of the structure-function relationships of ATIII and the correlation between molecular mutations and thrombosis. Analysis of these molecular defects was greatly simplified by enzymatic amplification of genomic DNA for the molecular characterization of a series of seven ATIII variants. Enzymatic amplification was followed by dot-blot analysis with ASO probes and sequencing of the

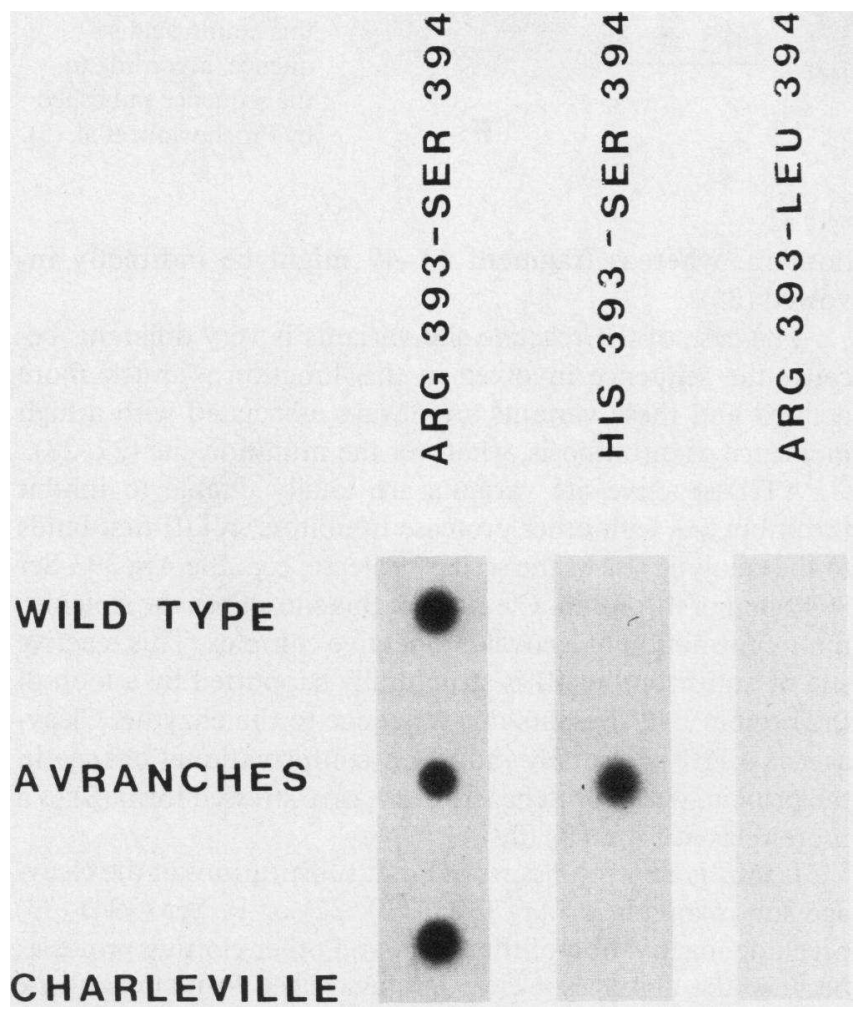

Figure 2. Analysis by dot blot of the amplified DNA from two patients with reactive-site variants. (Left) Reactive-site ATIII variants. (Top) ASO corresponding to the different 393-394 sequences. The samples were hybridized with either the wild-type probe (Arg 393Ser 394) or mutated probes: His 393, Leu 394, or Cys 393 (not shown). amplified material. The use of ASO probes specific for a panel of mutations already listed in ATIII variants ensured rapid detection of these mutations in six out of the seven variants. The homozygous or heterozygous state can also readily be assessed by this method, which can now be used for routine examination. Sequencing of all the amplified samples was necessary to confirm the mutations detected by dot-blot and is especially useful for identifying new mutations, as demonstrated by the ATIII Charleville variant.

Identification of the amino acid substitution responsible for these seven ATIII variants enabled us to reexamine several aspects of the structure of the two major functional domains of the ATIII protein (heparin binding site and serine protease reactive site) and the pathological impact of each mutation.

The five HBS variants included two Arg 47 Cys mutations (CGT to TGT) and three Pro 41 Leu mutations (CCG to CTG). Dot-blot analysis indicated that all the patients were heterozygous for the gene abnormality. The two heterozygous patients with Arg 47 Cys mutations had a history of DVT, whereas the three patients with Pro 41 Leu mutation were asymptomatic.

Mutations affecting the heparin binding site are usually associated with a low incidence of DVT. As shown in Table I, among 52 subjects with an HBS variant, only 5 had previously had a DVT, and 2 were homozygous. Our two patients with Arg 47 Cys mutations are heterozygous and both had a severe thrombotic history. Thus, although there is no definitive proof of an association between the type of mutation and the thrombotic tendency, this analysis does indicate that DVT is not present in subjects with heterozygous Pro 41 Leu mutation and that there is an increased risk of thrombosis with homozygous mutations and Arg 47 Cys mutation. However, the number of cases studied to date is limited and some heterozygous Arg 47 Cys subjects are asymptomatic (21).

The presence of a free cysteine in the protein could be responsible for this increase in the thrombotic tendency, as it may form disulfide bonds with other plasma proteins that would interfere with binding of ATIII to the glycosaminoglycans of the vascular wall.

The frequency of mutations involving the Pro 41 and Arg 47 among the HBS variants is potentially significant for several 

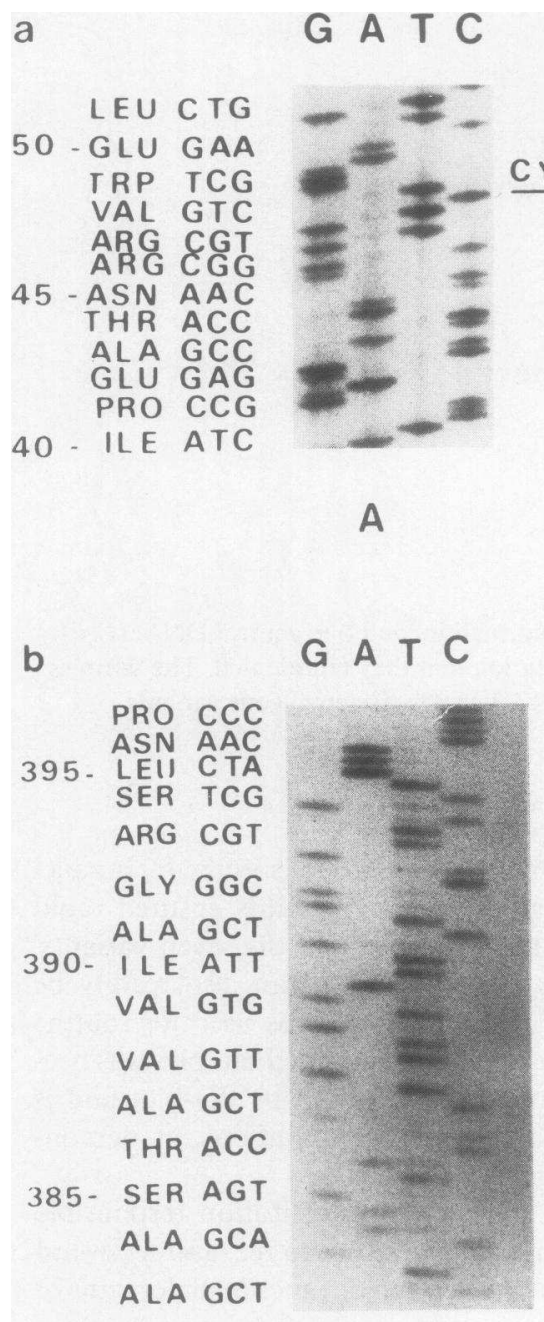

D

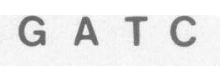

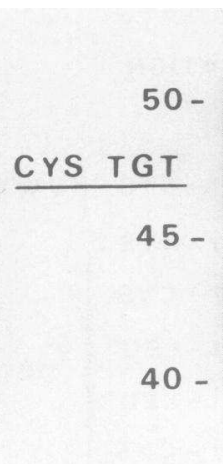

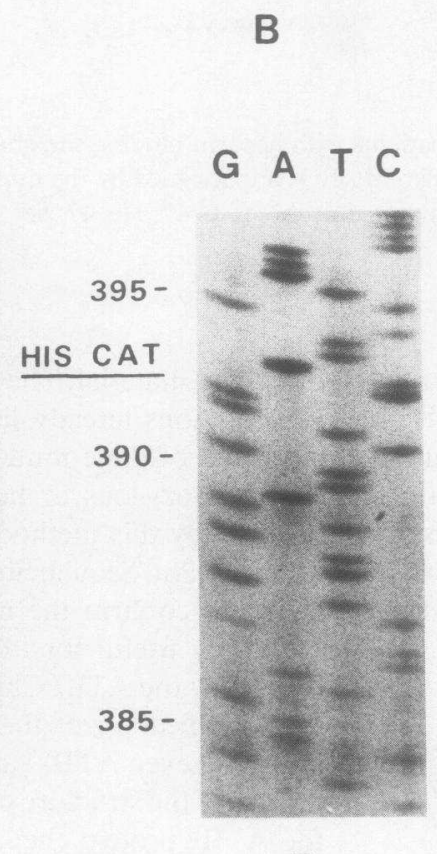

E

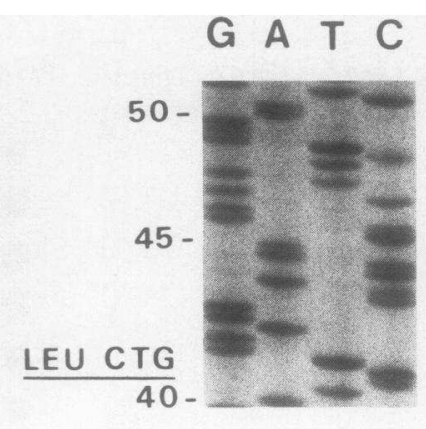

C

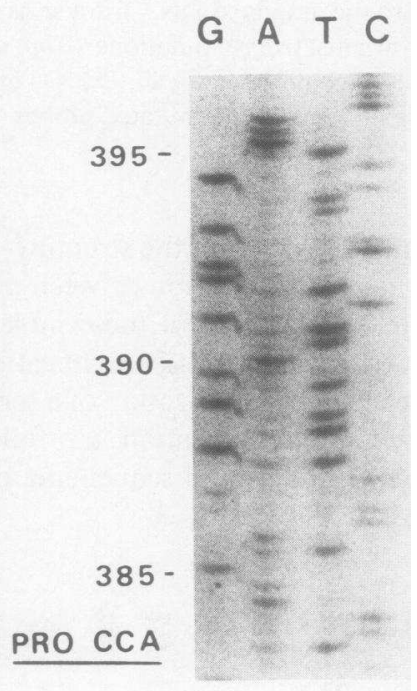

F
Figure 3. (a) Sequences of the heparin binding site. $(A)$ Wild-type; $(B)$ Arg 47 Cys mutation; (C) Pro 41 Leu mitation. (b) Sequences of the reactive center. $(D)$ Wild-type; $(E)$ Arg 393 His mutation; and $(F)$ Ala 384 Pro mutation. (Top) GATC indicates the dideoxynucleotide used in each sequencing reaction. Left of the nucleotide sequence autoradiography the following are indicated from right to left: (i) the nucleotide sequence; (ii) the corresponding amino acid sequence; and (iii) the number of this amino acid sequence, according to the sequence published by Prochownik et al. (5). reasons. First, these two amino acids are encoded by the codons CCG and CGT, both of which contain the CG dimer, which is a major site of methylation in human DNA. CG dimers might be mutation "hot spots" in the ATIII gene, as they are in the factor VIII gene (22). On the other hand, Arg 47 and Pro 41 might be critically important for heparin binding to ATIII. Several proteins can bind heparin through ionic interactions. ATIII is the only one that differentiates between lowand high-affinity heparin. The latter has an irregular sequence corresponding to a pentasaccharide, which is critical for ATIII binding. There must be a unique sequence in ATIII corresponding to this pentasaccharide. Perhaps this sequence includes Arg 47 and Pro 41, whose mutations are involved in 7 out of 12 families of HBS variants. However, a comparison of aminoacid sequences shows that Arg 47 is present in a homologous position in histidine-rich glycoprotein (23) and heparin cofactor II (24), two proteins that bind either low- or high-affinity heparin. ATIII models based on the three-dimensional structure of $\alpha_{1}$-antitrypsin indicate that the positively charged amino acids Arg 47, Lys 125, Arg 129, and Lys 133 are at the surface of the molecule and may be responsible for heparin binding through ionic interactions $(1,25)$. The fragment of ATIII, obtained by V8 protease digestion, which has the greatest affinity for high-affinity heparin, is 114-156; this fragment might represent part of the physiological heparin binding domain, whereas fragment 41-49 might be indirectly involved (26).

The case of the reactive-site variants is very different, because the sequence involved in this function is much more defined and these variants are always associated with a high incidence of thrombosis, whatever the mutation site $(27,28)$.

ATIII reactive-site variants are totally unable to inhibit thrombin. As with other protease inhibitors, ATIII first binds to the catalytic site of the serine-protease, e.g., the Arg 393-Ser 394 bond of thrombin. Cleavage at this site allows the stoichiometric formation of a covalent inactive complex. This reactive site of antithrombin III is structurally supported by a loop of the protein that presents this sequence to the enzyme. Cleavage of ATIII potentially induces a conformational change in the protein, which switches from a native stressed form (S) to a more relaxed form (R) (29).

It thus is easy to understand that substitutions at the cleavage site involving $P_{1}$ Arg $(393)(30,32)$ or $P_{1}^{\prime}$ Ser (394) (33) preclude inactivation of thrombin and other clotting protease, because the absence of cleavage makes the formation of the ATIII-thrombin irreversible complex impossible. One of the variants of our series, ATIII Avranches, was found to bear such a mutation (393 Arg to His), identical to those found in ATIII Sheffield (30) and A TIII Glasgow $(32,33)$. The latter also has a second biochemical defect: the variant was eluted from a hepa- 
rin-Sepharose column with $\mathrm{NaCl}$ concentrations higher than those required for normal ATIII. It was speculated that the $\mathbf{P}_{1}$ residue was indirectly involved in heparin binding and that the replacement of Arg by His may result in a conformational change more favorable to heparin binding (31). However, we could not reproduce these results with the Avranches variant, which coeluted with normal ATIII from a heparin-Sepharose column (13). This apparent discrepancy, also observed for ATIII Sheffield (30), may be due to technical differences and is presently under further investigation. However, it could also arise if one of the variants had an additional mutation, because the proteins have not been completely sequenced.

Antiprotease activity was also abolished by mutations located in the peptide sequences adjacent to the cleavage site. The Pro 407 Leu and Ala 382 Thr mutations observed in ATIII Utah and Hamilton $(34,35)$ are associated with a loss of antiprotease activity. These two amino acids are extremely conserved in the serpin family; thus the nature or the location (respectively in $\mathrm{P}_{14}^{\prime}$ and $\mathrm{P}_{12}$ ) of the substitution may modify the presentation or the structure of the loop, so that it can no longer react with the catalytic site of thrombin (Fig. 4). This view is supported by the fact that the two variants are not modified by thrombin and thus are probably not cleaved even though the cleavage site is intact.

This interpretation makes analysis of the last reactive-site variant, ATIII Charleville, identified as a Ala 384 Pro mutation, even more interesting. This variant has a unique biochemical behavior and cannot inactivate thrombin, as described previously (13). Briefly, there is an apparent shift in molecular mass from 58 to $62 \mathrm{kD}$ when ATIII Charleville is

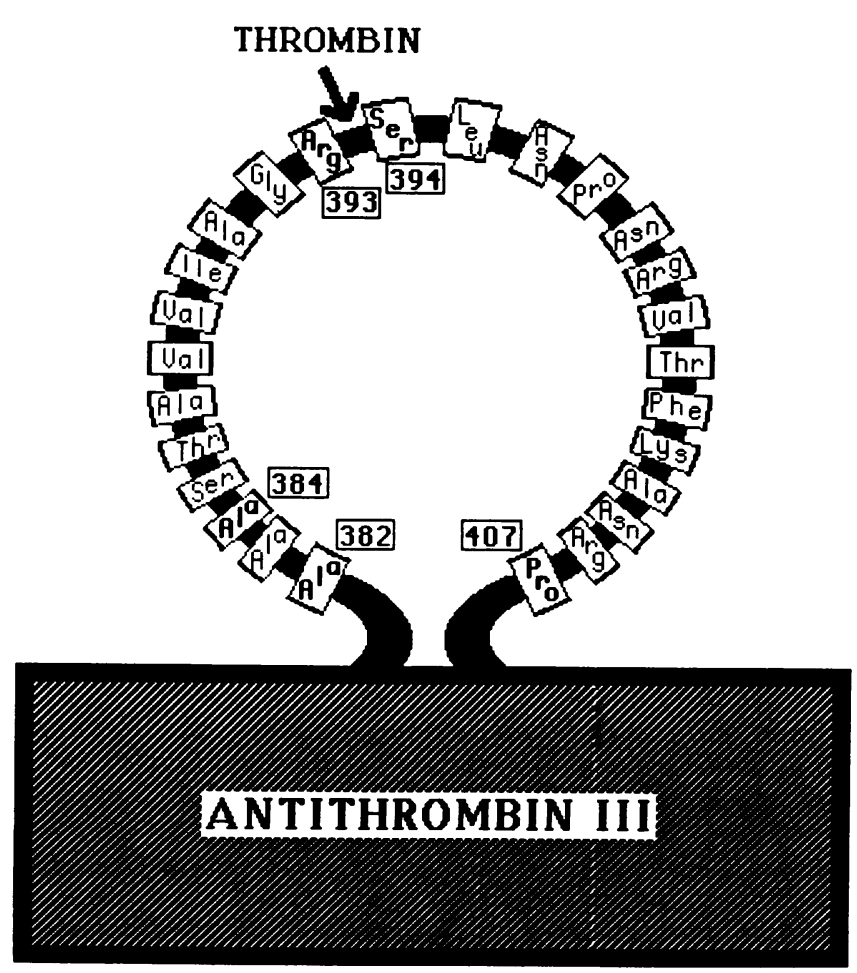

Figure 4. Schematic representation of the reactive site of ATIII. Arrow, cleavage site by thrombin. The amino acids 382,384 , and 407 might belong to the reactive site as their substitution impairs the protease inhibition. The mutations described are Ala $382 \mathrm{Thr}$ for ATIII Hamilton (35), Ala 384 Pro for ATIII Charleville (this work) and Pro 407 Leu for ATIII Utah (34). incubated with thrombin, whereas the migration of the native protein in SDS polyacrylamide gel remains normal.

These results, together with the fact that this variant corresponds to a new mutation of an amino acid located in the loop but different from the cleavage site, indicate that ATIII Charleville belongs to a new class of reactive-site mutant.

The biochemical data suggest that ATIII Charleville binds to and is cleaved by thrombin, since the in vitro interaction of the purified variant protein with thrombin increases the apparent molecular weight of the protein, probably by modifying the conformation of the molecule. Denaturing conditions decrease the molecular weight, probably by releasing the cleaved fragment. Nevertheless, this ATIII does not form stable covalent ATIII-thrombin complexes, as a consequence of the mutation of the Ala 384 to Pro. It thus is possible to consider ATIII Charleville, not as an inhibitor of thrombin, but as a substrate for the enzyme.

It is difficult to understand why this mutation is associated with such a functional modification. However, by analogy with the fact that ATIII is a substrate for elastase, which cleaves the loop of ATIII between $P_{1}$ and $P_{9}$, it may be that the new sequence, Pro-Ser-Thr (instead of Ala-Ser-Thr) competes with the regular sequence of the loop as a substrate for thrombin, and in this way prevents the variant ATIII being covalently linked to the enzyme. That the sequences of almost all thrombin substrates have a proline in position $P_{2}(36)$ favors this explanation. Sequencing of the $\mathrm{NH}_{2}$ terminus of the thrombin-modified form of this variant protein could help to clarify this situation.

In conclusion, ASO probes specific for all the mutations listed for ATIII variants can be used as a screening test allowing rapid detection of these mutations after enzymatic DNA amplification. Analysis of a large series of ATIII variants might lead to the discovery of a correlation between the site of mutation and the thrombotic risk. Sequencing is necessary to identify new mutations that contribute to the characterization of the reactive sites of ATIII. The new mutation in position 384, together with the previously reported mutations in position 382 and 407 indicate that additional amino acids are critical for thrombin inhibition.

\section{Acknowledgments}

We are indebted to Dr. C. Boyer-Neumann (Hôpital Bicètre, Paris), Dr. O. Chafa (Hôpital Mustapha, Algiers, Algeria), Dr. M. H. Denninger (Hôpital Beaujon, Paris), and Dr. M. Wolf (Hôpital Bicétre, Paris), for providing blood from patients with qualitative or quantitative ATIII deficiencies. We thank Prof. P. Corvol for helpful discussion. We also thank Nicole Braure and Annie Boisquillon for their excellent secretarial assistance.

Pascale Molho-Sabatier holds a "Coeur de Lyon" fellowship from the Credit Lyonnais Bank. We are indebted to Institut National de la Santé et de la Recherche Medicale (INSERM) for the constitution and the support of a clinical network (Réseau INSERM de Recherche en Santé Publique, 1986). Part of this work was also supported by a grant from the "Fonds d'Etudes et de Recherches du Corps Medical des Hôpitaux de Paris".

\section{References}

1. Carrell, R. W., P. B. Christey, and D. R. Boswell. 1987. Serpins: antithrombin and other inhibitors of coagulation and fibrinolysis. Evidence from aminoacid sequences. Thromb. Haemostasis. 57:1-15.

2. Rosenberg, R. D. 1975. Actions and interactions of antithrombin and heparin. N. Engl. J. Med. 292:146-151.

3. Björk, I., A. Danielsson, J. W. Fenton, and H. Jörnvall. 1981. 
The site in human antithrombin for functional proteolytic cleavage by human thrombin. FEBS (Fed. Eur. Biochem. Soc.) Lett. 126:257-260.

4. Bock, S. O., K. L. Wion, G. A. Vehar, and R. M. Lawn. 1982. Cloning and expression of the cDNA for human antithrombin III. Nucleic Acids Res. 10:8113-8125.

5. Prochownik, E. V., A. F. Markham, and S. H. Orkin. 1983. Isolation of a cDNA clone for human antithrombin III. J. Biol. Chem. 258:8389-8394.

6. Prochownik, E. V., S. C. Bock, and S. H. Orkin. 1985. Intron structure of the human antithrombin III gene differs from that of other members of the serine protease inhibitor superfamily. J. Biol. Chem. 260:9608-9612.

7. Chandra, T., R. Stackhouse, V. J. Kidd, and S. L. C. Woo. 1983. Isolation and sequence characterization of a cDNA clone of human antithrombin III. Proc. Natl. Acad. Sci. USA. 80:1845-1848.

8. Wolf, M., C. Boyer, J. M. Lavergne, and M. J. Larrieu. 1982. A new familial variant of antithrombin III: "Antithrombin III Paris." $\mathrm{Br}$ J. Haematol. 51:285-295.

9. Fischer, A. M., S. Beguin, C. Sternberg, and M. D. Dautzenberg 1987. Comparative effect of heparin and heparan sulphate on two abnormal antithrombin III type 3 variants. Br. J. Haematol. 66:213217.

10. Aiach, M., D. François, P. Priollet, L. Capron, M. Roncato, M. Alhenc-Gelas, and J. N. Fiessinger. 1987. An abnormal antithrombin III (ATIII) with low heparin affinity: ATIII Clichy. Br. J. Haematol. 66:515-522.

11. Fischer, A. M., P. Cornu, C. Sternberg, F. Mériane, M. D. Dautzenberg, O. Chafa, S. Beguin, and M. Desnos. 1986. Antithrombin III Alger: a new homozygous ATIII variant. Thromb. Haemostasis. 55:218-221.

12. Aiach, M., M. Nora, J. N. Fiessinger, M. Roncato, D. François, and $M$. Alhenc-Gelas. 1985. A functional abnormal antithrombin III (ATIII) deficiency: ATIII Charleville. Thromb. Res. 39:559-570.

13. Aiach, M., M. Roncato, G. Chadeuf, P. Dezellus, L. Capron, and J. N. Fiessinger. 1988. Antithrombin III Avranches, a new variant with defective serine-protease inhibition. Comparison with ATIII Charleville. Thromb. Haemostasis. 60:94-96.

14. Maxam, A. M., and W. Gilbert. 1980. Sequencing end-labeled DNA with base specific chemical cleavages. Methods Enzymol. 65:499-560.

15. Bell, G. I., J. H. Karam, and W. J. Rutter. 1981. Polymorphic DNA region adjacent to the $5^{\prime}$ end of the human insulin gene. Proc. Natl. Acad. Sci. USA. 78:5759-5763.

16. Saiki, R. K., D. H. Gelfand, S. Stoffel, S. J. Scharf, R. Higuchi, G. T. Horn, K. B. Mullis, and H. A. Erlich. 1988. Primer-directed enzymatic amplification of DNA with a thermostable DNA polymerase. Science (Wash. DC). 239:487-494.

17. Southern, E. M. 1975. Detection of specific sequences among DNA fragments separated by gel electrophoresis. J. Mol. Biol. 98:503-517.

18. Messing, J., and J. Vieira. 1982. A new pair of M13 vectors for selecting either DNA single strand or double-digest restriction fragments. Gene (Amst.). 19:269-276.

19. Sanger, F., S. Nicklen, and A. R. Coulson. 1977. DNA sequencing with chain terminating inhibitors. Proc. Natl. Acad. Sci. USA. 74:5463-5467.

20. Brunel, F., N. Duchange, A. M. Fischer, G. N. Cohen, and M. M. Zakin. 1987. Antithrombin III Alger: a new case of Arg47-Cyst mutation. Am. J. Hematol. 25:223-224.

21. Sakuragawa, N., K. Takahashi, S-i. Kondo, and T. Koide. 1983. Antithrombin III Toyama: A hereditary abnormal antithrombin III of a patient with recurrent phlebitis. Thromb. Res. 31:305-317.

22. Youssoufian, H., H. H. Kazazian, D. G. Phillips, S. Aronis, G. Tsiftis, V. A. Brown, and S. E. Antonarakis. 1986. Recurrent mutations in haemophilia $\mathrm{A}$ give evidence for $\mathrm{CpG}$ mutations hotspots. Nature (Lond.). 324:380-382.

23. Koide, K., D. Foster, and S. Odani. 1986. The heparin binding-site(s) of histidin-rich glycoprotein as suggested by sequence ho- mology with antithrombin III. FEBS (Fed. Eur. Biochem. Soc.) Lett. 194:242-244.

24. Blinder, M. A., J. C. Marasa, C. H. Reynolds, L. L. Deaven, and D. M. Tollefsen. 1988. Heparin cofactor II: cDNA sequence, chromosome localization, restriction fragment length polymorphism, and expression in Escherichia Coli. Biochemistry. 27:752-759.

25. Borg, J. Y., M. C. Owen, C. Soria, J. Soria, J. Caen, and R. W. Carrell. 1988. Arginine 47 is a prime heparin binding site in antithrombin. A new variant Rouen II, 47 Arg to Ser. J. Clin. Invest. 81:1292-1296.

26. Smith, J. W., and D. J. Knauer. 1987. A heparin-binding site in antithrombin III. Identification, purification and aminoacid sequence. J. Biol. Chem. 262:11964-11972.

27. Finazzi, G., R. Caccia, and T. Barbui. 1987. Different prevalence of thromboembolism in the subtypes of congenital antithrombin III deficiency: review of 404 cases. Thromb. Haemostasis. 58:1094.

28. Hultin, M. B., J. McKay, and U. Abilgaard. 1988. Antithrombin Oslo: Type 1b classification of the first reported antithrombin deficient family with a review of hereditary antithrombin variants. Thromb. Haemotasis. 59:468-473.

29. Carrell, R. W., and M. C. Owen. 1985. Plakalbumin, $a_{1}$-antitrypsin, antithrombin and the mechanism of inflammatory thrombosis. Nature (Lond.). 317:730-732.

30. Lane, D., H. Erdjument, A. Flynn, V. Di Marzo, M. Panico, H. R. Morris, M. Greaves, G. Dolan, and F. E. Preston. 1988. Antithrombin III Sheffield: aminoacid substitution at the reactive site (Arg 393 to His) causing thrombosis. Br. J. Haematol. 71:91-97.

31. Erdjument, H., D. A. Lane, M. Panico, V. Dimarzo, and H. R. Morris. 1988. Single aminoacid substitutions in the reactive site of antithrombin leading to thrombosis. Congenital substitution of arginine 393 to cysteine in antithrombin Northwick Park and to histidine in antithrombin Glasgow. J. Biol. Chem. 263:5589-5593.

32. Owen, M. C., C. H. Beresford, and R. W. Carrell. 1988. Antithrombin III Glasgow, 393 Arg to His: a P1 reactive site variant with increased heparin affinity but no thrombin inhibitory activity. FEBS (Fed. Eur. Biochem. Soc.) Lett. 231:317-320.

33. Stephens, A. W., B. S. Thalley, and C. H. W. Hirs. 1987. Antithrombin III Denver, a reactive site variant. J. Biol. Chem. 262:1044-1048.

34. Bock, S. C., J. A. Marrinan, and E. Radziejewska. 1988. Antithrombin III Utah: Proline-407 to leucine mutation in a highly conserved region near the inhibitor reactive site. Biochemistry. 27:61716178.

35. Devraj-Kizuk, R., D. H. K. Chui, E. V. Prochownik, C. J. Carter, F. A. Ofosu, and M. A. Blajchman. 1986. ATIII Hamilton: a gene with a point mutation (guanine to adenine) in codon 382 causing impaired serine protease reactivity. Blood. 72:1518-1523.

36. Mann, K. G., and R. L. Lunblab. 1987. Biochemistry of thrombin In Hemostasis and Thrombosis. R. W. Colman, J. Hirsh, V. J. Marder, and E. W. Salzman, editors. J. B. Lippincott Co., Philadelphia, PA. 148-161.

37. Chang, J. Y., and T. H. Tran. 1986. Antithrombin III Basel. Identification of a Pro-Leu substitution in a hereditary abnormal antithrombin with impaired heparin cofactor activity. J. Biol. Chem. 261:1174-1176.

38. Chassé, J. F., F. Esnard, J. D. Guitton, H. Mouray, F. Perigois, G. Fauconneau, and F. Gauthier. 1984. An abnormal antithrombin with no apparent affinity for heparin. Thromb. Res. 34:297-302.

39. Duchange, N., J. F. Chassé, G. N. Cohen, and M. M. Zakin. 1987. Molecular characterization of the antithrombin III Tours deficiency. Thromb. Res. 45:115-121.

40. Koide, T., S. Odani, K. Takahashi, T. Ono, and N. Sakuragawa. 1984. Antithrombin III Toyama: replacement of arginine 47 by cysteine in hereditary abnormal antithrombin III that lacks heparinbinding ability. Proc. Natl. Acad. Sci. USA. 81:289-293.

41. Owen, M. C., J. Y. Borg, C. Soria, J. Soria, J. Caen, and R. W. Carrell. 1987. Heparin binding defect in a new antithrombin III variant: Rouen, 47 Arg to His. Blood. 69:1275-1279. 